UDC: 532.53

\title{
MODELING OF FLOOD INUNDATION FOR ZHABAY RIVER BASIN IN CENTRAL KAZAKHSTAN REGION
}

\author{
Baktybekov K.S., Aimbetov A., Rakhimzhanov B.K. ${ }^{*}$, Murat A. \\ JSC "National Company "Kazakhstan Gharysh Sapary", Nur-Sultan, Kazakhstan, \\ rahimzhanovberik@gmail.com
}

\begin{abstract}
Frequency analysis is the estimation of how often a specified event will happen. This is the most important statistical technique in understanding the nature and magnitude of high discharge in a river. In this paper, the flood frequency of the Zhabay River Basin in the Central Kazakhstan Region is analyzed. The frequency analysis has been carried out using Gumbel's distribution on based the eightyear flood data in the Zhabay River Basin which was provided by the hydrometeorological service "Kazhydromet". The expected floods for various return periods $(T)$ is obtained. Additionally, the digital terrain model for the Zhabay River Basin is presented. This model was provided by the first Kazakhstan Earth remote sensing satellite KazEOSat-1. The results of the research would be useful in forecasting floods in the Central Kazakhstan region.
\end{abstract}

Keywords: modeling, floods, Zhabay River Basin, frequency analysis, Gumbel's distribution, KazEOSat -1.

\section{Introduction}

Flood is a natural hazard that may cause great damages to human civilization. It is studied worldwide using hydrologic as well as hydraulic models $[1,2]$. Flood frequency analysis (FFA) is the estimation of how often a specified event will occur. In order to obtain the probability distribution of flood analyzing before the estimation can be done the stream flows data are important. FFA is the universal method used for the estimation of the recurrent interval of any hydrological event that is pivotally essential for the management of flood with respect to planning, design, and operations through the use of fundamental knowledge of flood characteristics [3-5]. Much research has been done to analyze flood by methods such as GIS [6-8], Gumbel's distribution [9], L-moments [10], Powel distribution [11], Log-Normal, and the Log Pearson Type III distributions [12].

During spring floods, some territory of Kazakhstan suffers from flooding. For example, the city of Atbasar in the Akmola region has been regularly flooded for the past few years. In Atbasar the major floods were in 2014 and 2017. The threat came from the Zhabay River, where the water level rose sharply due to intense snowmelt. In 2014 and 2017, Atbasar has been declared a state of emergency (ES) of a natural nature. The damage in Atbasar was impressive. For example, in 2014, 330 houses were damaged, and in 2017 more than 650 objects were flooded, as well as livestock, agricultural land. Many residents lost all their property and were left without housing [13, 14]. Thus, a study of the flood inundation of the Zhabay River is a relevance area.

The aim of this research is to analyze the flood frequency for the Zhabay River Basin in the Central Kazakhstan region by applying Gumbel's distribution. Such distribution is used to represent the distribution of the maximum level of a river in a particular year if there was a list of maximum values for the past several years. It is also useful in predicting the chance that an extreme earthquake, flood, or other natural disasters will occur.

In work, we use peak flow discharges data that were provided by hydrometeorological service RSE "Kazhydromet" of the Ministry of Ecology, Geology and Natural Resources of the Republic of Kazakhstan [15]. By Gumbel's distribution, the research of flood inundation of the Zhabay River 
has not been studied before. We obtain a new result of the expected flood for different return periods for the Zhabay River. In addition, the digital terrain model for the Zhabay River Basin is presented. The results of research can be applied to predict future flood inundation in the city Atbasar.

\section{Materials and Methods}

\subsection{Study Area}

The study area is Zhabay River Basin that locates in Akmola region, Central Kazakhstan. The river locates between Latitude and Longitude as $52^{\circ} 19^{\prime} 0.16^{\prime \prime} \mathrm{N}-68^{\circ} 10^{\prime} 44.95^{\prime \prime} \mathrm{E}$, $52^{\circ} 15^{\prime} 35.81^{\prime \prime}-69^{\circ} 0^{\prime} 34.68^{\prime \prime} \mathrm{E}, 51^{\circ} 47^{\prime} 56.54^{\prime \prime} \mathrm{N}-68^{\circ} 13^{\prime} 30.54^{\prime \prime} \mathrm{E}, 51^{\circ} 48^{\prime} 55.84^{\prime \prime} \mathrm{N}-{ }^{\circ} 0^{\prime} 52.58^{\prime \prime} \mathrm{E}$. The Zhabay River is one of the large tributaries of the Esil (Ishim) River, flowing mainly in the Akmola Region, and is included in the Ishim River Basin. According to the latest data, the length of the river is $196 \mathrm{~km}$. The catchment area is $8800 \mathrm{~km}^{2}$. The river flows through the territories of the following settlements-Pokrovka, Borisovka, Atbasar (Atbasar district), Sandyktau, Balkashino (Sandyktau district) and also has 14 tributaries, such as Zhylandy, Aydabol, Sarymsakty.

In Fig. 1 we present digital terrain model for the Zhabay River Basin. The figure was produced with satellite KazEOSat-1 data of the JSC "National Company "Kazakhstan Gharysh Sapary". KazEOSat-1 is the first Kazakhstan Earth remote sensing satellite. The technological feature of KazEOSat-1 is the ability to shoot in stereo, which allows us to get digital terrain models. Digital terrain models are key components of flood modeling systems.

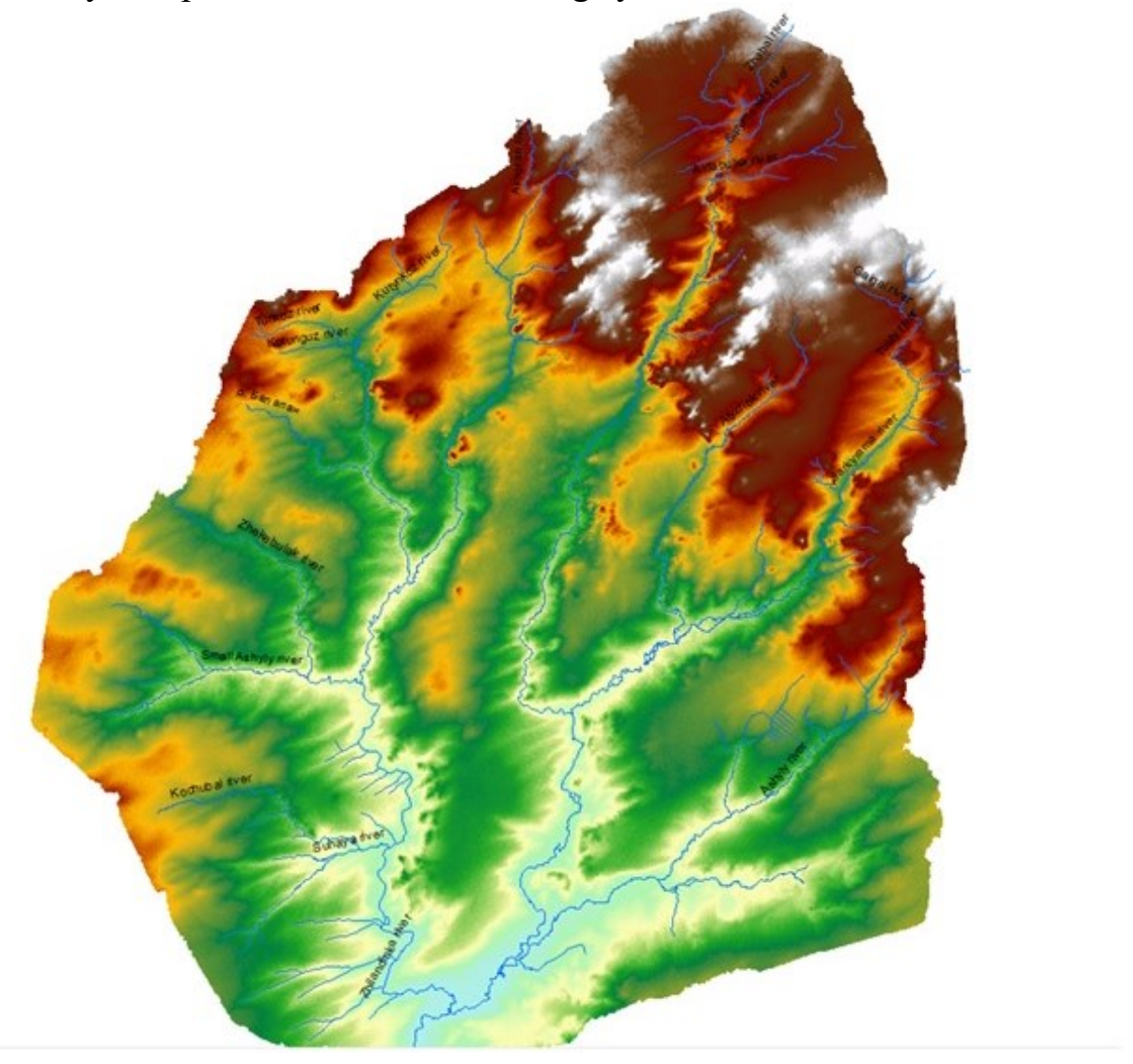

Fig. 1. Digital terrain model for the Zhabay River Basin that was produced with KazEOSat-1 data 


\subsection{Data Used}

For this research, the annual peak flood series data for 8 years varying over the period, 2011 to 2018 for the Zhabay River Basin were presented by hydrometeorological service RSE "Kazhydromet" [15]. In Table 1 we present the used peak flow discharges data in our research.

Table 1. Observed floods in corresponding years based on data [15]

\begin{tabular}{|c|c|c|}
\hline & Year & Peak flood in $^{\mathbf{3}} / \mathbf{s}$ \\
\hline 1 & 2011 & 202 \\
\hline 2 & 2012 & 246 \\
\hline 3 & 2013 & 194 \\
\hline 4 & 2014 & 1750 \\
\hline 5 & 2015 & 80,9 \\
\hline 6 & 2016 & 623 \\
\hline 7 & 2017 & 3290 \\
\hline 8 & 2018 & 154 \\
\hline
\end{tabular}

\subsection{Gumbel's distribution}

In 1941 E. J. Gumbel began developing the method of an extreme-value probability distribution to analyze the magnitude frequency relation of annual peak discharges. Until now his method still enjoys great favor among hydrologist-statisticians. The Gumbel's distribution method is used to analyze the extreme value of different return period of 10 years, 20 years, 50 years and 100 years using observed discharged data. In research, we apply Gumbel's distribution to carry out the flood frequency analysis of the Zhabay River Basin using 8 years annually peak flow data (2011-2018). In this method, the variate $x$ (flood peak discharge) with recurrence interval $T$ is given by

$$
x_{T}=\bar{x}+K s_{n-1},
$$

where $x_{T}$ is flood peak discharge, $\bar{x}$-average value $x, s_{n-1}$-standart devivation that defined by

$$
s_{n-1}=\sqrt{\frac{\sum(x-\bar{x})^{2}}{N-1}}
$$

here $K-$ is the frequency factor expressed as

$$
K=\frac{y_{T}-\overline{y_{n}}}{\sigma_{n}}
$$

here $y_{T}$ - is the reduced variate that is given by

$$
y_{T}=-\ln \left[\ln \left[\frac{T}{T-1}\right]\right],
$$

where $\overline{y_{n}}$ - Gumbel's reduce mean variable, which defined from Gumbel's Table $2 ; \sigma_{n}$-reduce standard deviation, a function of sample size $n$ that defined from Gumbel's Table 2.

The data in Table 2 were obtained by Gumbel [16] and we apply these data to obtain frequency factor $K$ by equation (3). Because our period of study is 8 year we use case $n=8$. It is mean that from Table 2 we apply reduced mean variable $\overline{y_{n}}=0.4843$ and reduce standard deviation $\overline{\sigma_{n}}=0.9043$. 
Table 2. Gumbel's reduced mean variable and standard deviation based on data number [16]

\begin{tabular}{|c|c|c|c|c|c|c|c|c|}
\hline$n$ & $\overline{y_{n}}$ & $\sigma_{n}$ & $n$ & $\overline{y_{n}}$ & $\sigma_{n}$ & $n$ & $\overline{y_{n}}$ & $\sigma_{n}$ \\
\hline 8 & 0.4843 & 0.9043 & 16 & 0.5157 & 1.0316 & 24 & 0.5296 & 1.0864 \\
\hline 9 & 0.4902 & 0.9288 & 17 & 0.5181 & 1.0411 & 25 & 0.5309 & 1.0915 \\
\hline 10 & 0.4952 & 0.9497 & 18 & 0.5202 & 1.0493 & 26 & 0.5320 & 1.0961 \\
\hline 11 & 0.4996 & 0.9676 & 19 & 0.5220 & 1.0566 & 27 & 0.5332 & 1.1004 \\
\hline 12 & 0.5035 & 0.9833 & 20 & 0.5236 & 1.0628 & 28 & 0.5343 & 1.1047 \\
\hline 13 & 0.5070 & 0.9972 & 21 & 0.5252 & 1.0698 & 29 & 0.5353 & 1.1086 \\
\hline 14 & 0.5100 & 1.0095 & 22 & 0.5268 & 1.0754 & 30 & 0.5362 & 1.1124 \\
\hline 15 & 0.5128 & 1.0206 & 23 & 0.5283 & 1.0811 & 31 & 0.5371 & 1.1159 \\
\hline
\end{tabular}

\section{Results and discussions}

Gumbel's distribution is applied to carry out the flood frequency analysis of the Zhabay River using 8 years annually peak flow data (2011-2018). The maximum flood of $3290 \mathrm{~m}^{3} / \mathrm{s}$ was recorded in 2017 whereas the lowest flood of $154 \mathrm{~m}^{3} / \mathrm{s}$ occurred in 2018 . The mean flood is $817.45 \mathrm{~m}^{3} / \mathrm{s}$. Based on the Gumbel's distribution described in section 1.3, the important parameters as return period, probability, reduced variate were computed in Table 3 while Table 4 shows the various discharges expected alongside their return periods.

Table 3. Computation results by Gumbel's distribution

\begin{tabular}{|c|c|c|c|c|c|c|}
\hline $\mathrm{N}$ & Water year, $\mathrm{x}$ & Flood peak & Oder $(\mathrm{m})$ & $\begin{array}{c}\text { Return } \\
\text { Period }\end{array}$ & Probability & $\begin{array}{c}\text { Reduced } \\
\text { Variate }\end{array}$ \\
\hline 1 & 2011 & 202 & 1 & 9 & 0.11 & 2.14 \\
\hline 2 & 2012 & 246 & 2 & 4.5 & 0.22 & 1.38 \\
\hline 3 & 2013 & 194 & 3 & 3 & 0.33 & 0.90 \\
\hline 4 & 2014 & 1750 & 4 & 2.25 & 0.44 & 0.53 \\
\hline 5 & 2015 & 80.9 & 5 & 1.8 & 0.56 & 0.21 \\
\hline 6 & 2016 & 623 & 6 & 1.5 & 0.67 & -0.09 \\
\hline 7 & 2017 & 3290 & 7 & 1.29 & 0.78 & -0.41 \\
\hline 8 & 2018 & 154 & 8 & 1.13 & 0.89 & -0.79 \\
\hline
\end{tabular}

Table 4. Computation of expected flood for the Zhabay River

\begin{tabular}{|c|c|c|c|}
\hline $\begin{array}{c}\text { Return Period, } \\
\mathrm{T} \text { ( in years) }\end{array}$ & Reduced Variate, $y_{T}$ & $\begin{array}{c}\text { Frequency } \\
\text { Factor, } \mathrm{K}\end{array}$ & $\begin{array}{c}\text { Expected Flood, } \\
\mathrm{x}_{\mathrm{T}}\end{array}$ \\
\hline 2 & 0.37 & -0.13 & 669.0 \\
\hline 5 & 1.50 & 1.12 & 2097.88 \\
\hline 10 & 2.25 & 1.95 & 3043.92 \\
\hline 25 & 3.20 & 3.00 & 4239.26 \\
\hline 50 & 3.90 & 3.78 & 5126.02 \\
\hline 100 & 4.60 & 4.55 & 6006.24 \\
\hline 200 & 5.30 & 5.32 & 6883.24 \\
\hline 250 & 5.52 & 5.57 & 7165.19 \\
\hline 500 & 6.21 & 6.34 & 8040.28 \\
\hline 1000 & 6.91 & 7.10 & 8914.75 \\
\hline
\end{tabular}


In Table 4, the frequency factor $K$ is calculated based on equation (3). Moreover, Gumbel's reduced mean variable $\overline{y_{n}}$ and standard deviation $\overline{\sigma_{n}}$ can be selected using Table 2 in case $n=8$. The reduced variate $y_{T}$ and expected flood $x_{T}$ are calculated by equations (4) and (1). Analyze the results in Table 4 we see that in case $T=2$ expected flood in Zhabay River is $669 \mathrm{~m}^{3} / \mathrm{s}$. It is almost the same amount as in the 2016 year. However, our result shows that in the case of return period $T \geq 5$ we can assume the next flood inundation of the Zhabay river because the expected flood is $2097.88 \mathrm{~m}^{3} / \mathrm{s}$ and more. This amount of water is bigger than observed in the 2014 year and 2017 year when in city Atbasar was declared a state of emergency of a natural nature because of flood inundation in the Zhabay River.

\section{Conclusion}

In this paper, flood frequency analysis had been carried out for the Zhabay River Basin in Central Kazakhstan region using peak flow data. The observed data (Table 2) were provided by hydrometeorological service RSE "Kazhydromet” of the Ministry of Ecology, Geology and Natural Resources of the Republic of Kazakhstan. According to the 8 years history of the Zhabay River, the maximum outcome in 2017 the amount of flood discharge is $3290 \mathrm{~m}^{3} / \mathrm{s}$. And the second maximum flood discharge happens in 2014 with the amount of flood discharge $1750 \mathrm{~m}^{3} / \mathrm{s}$.

In work, we used Gumbel's distribution that is a statistical method often used for predicting extreme hydrological events such as floods. What is different from other methods is that the value of frequency factor $K$ depends upon the number of years of record. In this research, the estimation of frequency factor $K$ using $\mathrm{n}=8$.

We performed a flood frequency analysis of the Zhabay River using annual peak flow or maximum discharge data obtained in the river for the years 2011-2018 (Table 2). The results in Table 4 show the expected floods in the river reach for return periods of $2 \mathrm{yrs}$, $5 \mathrm{yrs}, 10 \mathrm{yrs}$, 25yrs, $50 \mathrm{yrs}, 100 \mathrm{yrs}, 200 \mathrm{yrs}, 250 \mathrm{yrs}, 500 \mathrm{yrs}$, and 1000yrs. By analyzing the result in Table 4 we predict that the next higher flood inundation will be in return period $T=5$ with the amount $2097.88 \mathrm{~m}^{3} / \mathrm{s}$. We assume that the reason floods are the global impacts of climate change and the effects of transboundary waters (water comes to us).

In addition in Fig.1, we present the digital terrain model for the Zhabay River Basin. This model was produced with Kazakhstan Earth remote sensing satellite KazEOSat-1 of the JSC "National Company "Kazakhstan Gharysh Sapary".

\section{Acknowledgements}

The research was supported by the Ministry of Education and Science of the Republic of Kazakhstan, Grant number: AP05133188

\section{REFERENCES}

1 Duisenbai N., Baktybekov K., Aimbetov A., Tuleukulova D., Rakhimzhanov B. Development and implementation of scientific based methodology of predicting and modeling of flood and inundation using kazeosat-1, 2 space craft remote sensing datas. Proceedings of the Intern. Multidisciplinary Scient. Geo Conf. "Surveying Geology and Mining Ecology Management SGEM", 2018, Vol. 18, pp. 253 - 258.

2 Manfreda S., Nardi F., Samela C., Grimaldi S., et al. Investigation on the Use of Geomorphic Approaches for the Delineation of Flood Prone Areas. Journal of Hydrology, 2014, Vol. 517, pp. 863-876.

3 Ling Kang L., Jiang Sh., Hu X., Li, Ch. Evaluation of Return Period and Risk in Bivariate NonStationary Flood Frequency Analysis. Water, 2019, Vol.11, pp.79-83.

4 Odunuga Sh., Raji SA. Flood Frequency Analysis and Inundation Mapping of Lower Ogun River Basin. Journal of Water Resource and Hydraulic Engineering, 2014, Vol.3, pp. 48-59.

5 Plekhanov P.A., Medeu N.N. Extreme hydrological phenomena in the Essil river basin: genesis, general patterns of manifestation. Journal of ecological Engineering, 2019, Vol.20, No, 7 , pp. 187-195. 
6 Domeneghetti A., Schumann G.J, Tarpanelli, A. Preface: Remote Sensing for Flood Mapping and Monitoring of Flood Dynamics. Remote Sens., 2019, Vol.11, No. 8, pp. 943-948.

7 Feloni E.G., Mousadis I., Baltas E. Flood vulnerability assessment using a GIS-based multi-criteria approach. The case of Attica region. Journal of Flood Risk Management, 2019, Vol.13, pp. $1-15$.

8 Houessou-Dossou E.A., Gathenya J.M., Njuguna M., Gariy Z.A. Flood frequency analysis using participatory GIS and Rainfall data for stations in Narok Town, Kenya. Hydrology, 2019, Vol.6, pp.90-94.

9 Bharali B. A Study on Frequency Analysis for Puthimari Catchment by Gumbel Distribution Method. Journal of Civil Engineering and Environmental Technology, 2015, Vol.2, pp. 19 - 22.

10 Noto L. V, La Loggia G. Use of L-Moments Approach for Regional Flood Frequency Analysis in Sicily, Italy. Water Resour. Manag., 2009, Vol.23, pp. 2207-2211.

11 Rakhimzhanov B.K., Murat A., Shaikhova G.N. Flood estimation for Zhabay River Basin in Akmola Region. Journal of Physics: Conference Series 2019, Vol.1391, pp. 012168 (1-5).

12 Izinyon O. C., Ihimekpen N., Igbinoba G. E. Flood Frequency Analysis of Ikpoba River Catchment at Benin City Using Log Pearson Type III Distribution. Journal of Emerging Trends in Engineering and Applied Sciences, 2011, Vol. 2, No. 1, pp. 50-55.

13 Fakhrudenova I.B., Petrova L.E. Floods on the Zhabai river in Atbasar town: Consequeces, causes, recommendations for reducing the risk of flood Materials of International practical science conference " Shoqan Oqulary - 22",2018,. Vol. 6, pp. 234-239, [in Russian]

14 Website: An unprecedented flood overwhelmed Atbasar: the dam was destroyed. Available at: https://ru.sputniknews.kz/regions/20170417/2031784/nebyvaloe-polovode-zahlestnulo-atbasar-razrushenaplotina.html [in Russian]

15 Date from the hydrometeorological service RSE "Kazhydromet" of the Ministry of Ecology, Geology and Natural Resources of the Republic of Kazakhstan. Available at: https://www.kazhydromet.kz/, 2019.

16 Onen F, Bagatur T. Prediction of Flood Frequency Factor for Gumbel Distribution Using Regression and GEP Model. Arab J. Sci. Eng., 2017, Vol.42, pp. 3895-3906. 